\title{
Ten-year experience of esophageal endoscopic submucosal dissection of superficial esophageal neoplasms in a single center
}

Hyung Chul Park ${ }^{1,}$, Do Hoon Kim ${ }^{2,}$, Eun Jeong Gong ${ }^{2}$, Hee Kyong $\mathrm{Na}^{2}$, Ji Yong Ahn ${ }^{2}$, Jeong Hoon Lee ${ }^{2}$, Kee Wook Jung ${ }^{2}$, Kee Don $\mathrm{Choi}^{2}$, Ho June Song ${ }^{2}$, Gin Hyug Lee ${ }^{2}$, Hwoon-Yong Jung ${ }^{2}$, and Jin-Ho Kim²

Departments of ${ }^{1}$ Internal Medicine and ${ }^{2}$ Gastroenterology, Asan Medical Center, University of Ulsan College of Medicine, Seoul, Korea

\author{
Received: July 10, 2015 \\ Revised : August 24, 2015 \\ Accepted: August 29, 2015

\section{Correspondence to} \\ Hwoon-Yong Jung, M.D. \\ Department of Gastroenterology, \\ Asan Medical Center, University \\ of Ulsan College of Medicine, 88 \\ Olympic-ro 43-gil, Songpa-gu, \\ Seoul 05505, Korea \\ Tel: +82-2-3010-3197 \\ Fax: +82-2-476-0824 \\ E-mail: hyjung@amc.seoul.kr
}

*These authors contributed equally to this work.
Background/Aims: Endoscopic submucosal dissection (ESD) of a superficial esophageal neoplasm (SEN) is a technically difficult procedure. We investigated the clinical outcomes of ESD to determine its feasibility and effectiveness for the treatment of SEN.

Methods: Patients who underwent ESD for SEN between August 2005 and June 2014 were eligible for this study. The clinical features of patients and tumors, histopathologic characteristics, adverse events, results of endoscopic resection, and survival were investigated.

Results: ESD was performed in 225 patients with 261 lesions, including 70 cases $(26.8 \%)$ of dysplasias and 191 cases $(73.2 \%)$ of squamous cell carcinomas. The median age was 65 years (range, 44 to 86 ), and the male to female ratio was 21.5:1. Median tumor size was $37 \mathrm{~mm}$ (range, 5 to 85 ) and median procedure time was 45 minutes (range, 9 to 160 ). En bloc resection was performed in 245 of 261 lesions (93.9\%), with complete resection in 234 lesions (89.7\%) and curative resection in 201 lesions (77.0\%). Adverse events occurred in 33 cases (12.6\%), including bleeding $(1.5 \%)$, perforation (4.6\%), and stricture (6.5\%). During a median follow-up period of 35.0 months (interquartile range, 18 to 62 ), none of the patients showed local recurrence. The 5 -year overall and disease-specific survival rates were $89.7 \%$ and $100 \%$, respectively.

Conclusions: ESD is a feasible and effective procedure for the treatment of SEN based on our 10-year experience, which showed favorable outcomes.

Keywords: Esophageal neoplasms; Endoscopic submucosal dissection; En bloc resection

\section{INTRODUCTION}

Esophageal cancer is among the 10 most common cancers and is the seventh most common cause of cancer-related death in men worldwide [1,2]. Although the incidence of adenocarcinoma has been increasing in Western countries, the proportion of squamous cell carcinoma (SCC) is more than that of adenocarcino$\mathrm{ma}$, and esophageal cancer is the tenth most common cause of cancer-related death in Korea [3]. Widespread endoscopic screening and the development of new endoscopic techniques have improved the detection rate of superficial esophageal neoplasms (SENs), including early esophageal cancer [4-6]. Surgical esophagectomy 
with lymph node dissection is the treatment of choice for esophageal SCC [7-9]. However, esophagectomy is associated with high morbidity and mortality rates $[8,9]$; therefore, endoscopic resection (ER) was developed as an alternative procedure for the treatment of SENs because it is minimally invasive and maintains patients' quality of life.

Originally, endoscopic mucosal resection (EMR) was the standard procedure and showed satisfactory results in the treatment of SENs [10-14]. However, the piecemeal resection (PR) during EMR, especially in the cases of large lesions, resulted in a high local recurrence rate of $24 \%$ to $26 \%$ [11-19]. Endoscopic submucosal dissection (ESD) enables en bloc resection (EnR) of SENs regardless of size $[15,20]$, and studies regarding the long-term outcomes of ESD reported satisfactory results [21-25]. We previously reported the clinical outcomes of ER including EMR and ESD for esophageal neoplasm and showed favorable outcomes [26]. In the present study, we investigated the clinical outcomes of ESD for the treatment of SENs by analyzing a large number of patients over a relatively long-term follow-up period.

\section{METHODS}

\section{Patients}

Patients who underwent ESD for the removal of SENs at Asan Medical Center between August 2005 and June 2014 were eligible in this study. SENs included dysplasia and superficial SCC confined to the mucosal layer. Patients who were previously diagnosed and treated with esophageal neoplasm or recurrent esophageal neoplasms were excluded. Pre-procedural diagnostic workup included white-light endoscopy (WLE), narrow band imaging (NBI), and Lugol chromoendoscopy (LCE). Endoscopic ultrasound was performed to evaluate the exact depth of invasion in patients with SCC. All patients with SCCs underwent computed tomography (CT) scans of the chest and upper abdomen, and positron emission tomography (PET)-CT scans to identify possible distant metastasis or lymph node metastasis.

Clinical characteristics, including patient-related, tumor-related (the location and size of the lesions, and histologic diagnosis), and procedure-related (procedure time and adverse events) factors, were collected using medical records. In addition, the clinical outcomes of ER, including complete resection (CR) and curative resection (CuR) rates, local recurrence rates, the development of synchronous or metachronous lesions, and the overall and disease-specific survival rates, were investigated. Informed consent was obtained from all patients before ER, and the retrospective analysis was approved by the Institutional Review Board of Asan Medical Center (2011-0793).

\section{Endoscopic treatment}

ESD was performed by five experienced endoscopists (J.H.Y., S.H.J., C.K.D., L.J.H., and K.D.H.) on patients placed under conscious sedation or general anesthesia using forward-viewing endoscopy (GIF-H26o, Olympus, Tokyo, Japan). The tip of the endoscope was fitted with a transparent attachment (D-201-11814, Olympus) to obtain a constant endoscopic view and to create tension on the connective tissue during submucosal dissection.

Before ER, an endoscopic examination was performed by WLE, NBI, and LCE through the direct instillation of $20 \mathrm{~mL}$ of $3 \%$ Lugol's solution to evaluate the lateral extent of tumors. Lesion borders were marked, and normal saline containing small amounts of $0.005 \%$ epinephrine and indigo carmine was injected submucosally. A small incision was made with a hook knife (Olympus), followed by a circumferential mucosal incision outside the markings. The submucosal connective tissue immediately beneath the lesion was dissected from the muscularis propria with an insulated-tip (IT) knife (Olympus) or nano-IT knife (Olympus). Submucosal injection was repeated as needed, and further dissection was performed to ensure a deep resection margin. Hemostasis was performed during or after the dissection using hemostatic forceps (FD-41oLR, Olympus).

Follow-up endoscopy was performed every 6 months during the first 2 years after ER and annually thereafter. When SCC was detected, patients underwent additional CT scans of the chest and abdomen. PET-CT scans were performed at 1, 3, and 5 years after ER.

\section{Histopathologic evaluation}

The resected specimens were fixed in formalin and serially sectioned perpendicularly at $2 \mathrm{~mm}$ intervals. The size of the resected specimens and tumors, depth of invasion, presence of lymphovascular invasion (LVI) or 
perineural invasion, histologic differentiation, and resection margins were evaluated. All sections were subjected to detailed pathologic review according to the guidelines of Clinical and Pathological Studies in Carcinoma of the Esophagus [27,28]. Based on these guidelines, tumors were classified into five categories according to the depth of invasion as follows: To, dysplasia; m1, intraepithelial carcinoma; m3, tumor extremely close to or infiltrating the muscularis mucosa; and $\mathrm{m} 2$, tumors located between $\mathrm{m} 1$ and $\mathrm{m} 3$. Submucosal invasion (SMI) was defined as a tumor extending beyond the muscularis mucosa, including Smı. Smı was defined as a submucosally invaded tumor that extended up to $200 \mu \mathrm{m}$ below the lower border of the muscularis mucosa [29].

\section{DEFINITIONS}

EnR was defined as the resection of a targeted lesion in one piece regardless of the depth of invasion and LVI. $\mathrm{CR}$ was defined as tumor-free lateral margins $>2 \mathrm{~mm}$ and tumor-free vertical margins $>0.5 \mathrm{~mm}$ on histologic examination. A multi-fragment section was regarded as CR when all fragments could be evaluated adequately after achieving perfect reconstruction. If the lateral margin of the lesion could not be evaluated histologically because of the effect of the electrosurgical current or mechanical damage, the resection was regarded as incomplete.

CuR was defined as the absence of a poorly differentiated component, LVI, perineural invasion, or SMI in an en bloc resected case. Non-CuR was defined as a tumor that did not fulfill the above criteria for CuR regardless of CR.

Local recurrence was defined as an iodine-unstained area that was detected at the site of resection and confirmed histologically. Synchronous lesions were defined as those detected in a different location within 1 year of the initial ER, and metachronous lesions were those detected more than 1 year after ER.

Complications included bleeding, perforation, and postoperative stricture. Procedure-related bleeding was defined as follows: (1) bleeding confirmed by routine second look endoscopy within 24 hours; (2) clinical evidence of melena or hematemesis; or (3) massive bleeding such as that requiring transfusion after the level of he- moglobin fell by 2 g/dL. Perforation was diagnosed endoscopically during the procedure when the mediastinal connective tissue could be visualized or radiographically as the presence of free air on chest radiography. Stricture was defined as the inability to pass a standard 11 $\mathrm{mm}$ diameter endoscope through the stricture.

\section{Statistical analysis}

The index date was defined as the date of the first ESD. Patients were followed up from the index date to death or the last follow-up date (August 12, 2014). Differences between two groups were determined using chi-square test. Kaplan-Meier analysis and the log-rank test were used to assess survival. All statistical analyses were performed using SPSS version 18.0 (SPSS Inc., Chicago, IL, USA), and $p<0.05$ was considered statistically significant.

\section{RESULTS}

\section{Clinicopathologic characteristics}

During the study period, 225 patients underwent ESD for 261 lesions, including 70 dysplasias (26.8\%) and 191 SCCs $(73.2 \%)$ (Table 1). The median age was 65 years (range, 44 to 86), and the male to female ratio was 21.5:1. Eleven lesions (4.2\%) were located in the upper esophagus, 156 (59.8\%) in the middle esophagus, and 94 (36.0\%) in the lower esophagus. Of the 191 SCCs, 172 (90.0\%) were confined to the mucosal layer and 19 (10.0\%) had invaded the submucosal layer. Among these, 11 lesions (4.2\%) occupied more than three-fourths of the luminal circumference.

\section{Endoscopic and oncologic outcomes of endoscopic submucosal dissection}

Endoscopic outcomes were evaluated at 261 lesions. The median size of lesions was $18.8 \mathrm{~mm}$ (range, 2 to 75 ) and that of resected specimens was $37 \mathrm{~mm}$ (range, 5 to 85 ). The median procedure time was 45 minutes (range, 9 to 160). EnR was achieved in 245 lesions (93.9\%), CR in 234 lesions (89.7\%), and CuR in 201 lesions (77.0\%) (Fig. 1).

Adverse events occurred in 33 cases (12.6\%) including bleeding $(n=4,1.5 \%)$, perforation $(n=12,4.6 \%)$, and stricture $(n=17,6.5 \%)$. All patients with delayed bleeding were treated endoscopically. Six patients diagnosed 
Table 1. Characteristics of the patients with superficial esophageal neoplasms $(n=225)$

\begin{tabular}{|c|c|}
\hline Characteristic & Value \\
\hline Age, yr & $65(44-86)$ \\
\hline Sex, mela:female & $215: 10$ \\
\hline \multicolumn{2}{|l|}{ Smoking } \\
\hline Current smoker & $90(34 \cdot 5)$ \\
\hline Ex-smoker & $129(49.4)$ \\
\hline Non-smoker & $42(16.1)$ \\
\hline \multicolumn{2}{|l|}{ Alcohol } \\
\hline Alcoholics & $133(51)$ \\
\hline Ex-alcoholics & $90(34.5)$ \\
\hline Non-alcoholics & $38(14.6)$ \\
\hline \multicolumn{2}{|l|}{ Lesion characteristics $(n=261)$} \\
\hline \multicolumn{2}{|l|}{ Location } \\
\hline Upper esophagus & $11(4.2)$ \\
\hline Middle esophagus & $156(59.8)$ \\
\hline Lower esophagus & $94(36)$ \\
\hline \multicolumn{2}{|l|}{ Histology } \\
\hline Dysplasia & $70(26.8)$ \\
\hline Squamous cell carcinoma & $191(73.2)$ \\
\hline Lesion size, $\mathrm{mm}$ & $18.8(2-75)$ \\
\hline Resected specimen size, $\mathrm{mm}$ & $37(5-85)$ \\
\hline Procedure time, min & $45(9-160)$ \\
\hline \multicolumn{2}{|l|}{ Histologic depth of invasion } \\
\hline To & $70(26.8)$ \\
\hline $\mathrm{m} 1$ & $86(33)$ \\
\hline $\mathrm{m} 2$ & $67(25 \cdot 6)$ \\
\hline $\mathrm{m} 3$ & $19(7 \cdot 3)$ \\
\hline $\mathrm{Sm}$ & $19(7 \cdot 3)$ \\
\hline \multicolumn{2}{|l|}{ Circumference, \% } \\
\hline$<50$ & $198(75 \cdot 9)$ \\
\hline $50-75$ & $52(19.9)$ \\
\hline$>75$ & $11(4.2)$ \\
\hline En bloc resection & $245(93.9)$ \\
\hline Complete resection & $234(89.7)$ \\
\hline Curative resection & $201(77.0)$ \\
\hline Complication & $33(12.6)$ \\
\hline Bleeding & $4(1.5)$ \\
\hline Perforation & $12(4 \cdot 6)$ \\
\hline Stricture & $17(6.5)$ \\
\hline
\end{tabular}

Values are presented as median (range) or number (\%).

To, dysplasia; $\mathrm{m} 1$, intraepithelial carcinoma; m2, tumors located between $\mathrm{m}_{1}$ and $\mathrm{m}_{3}$; $\mathrm{m}_{3}$, tumor extremely close to or infiltrating the muscularis mucosa; Sm, submucosal invasion.

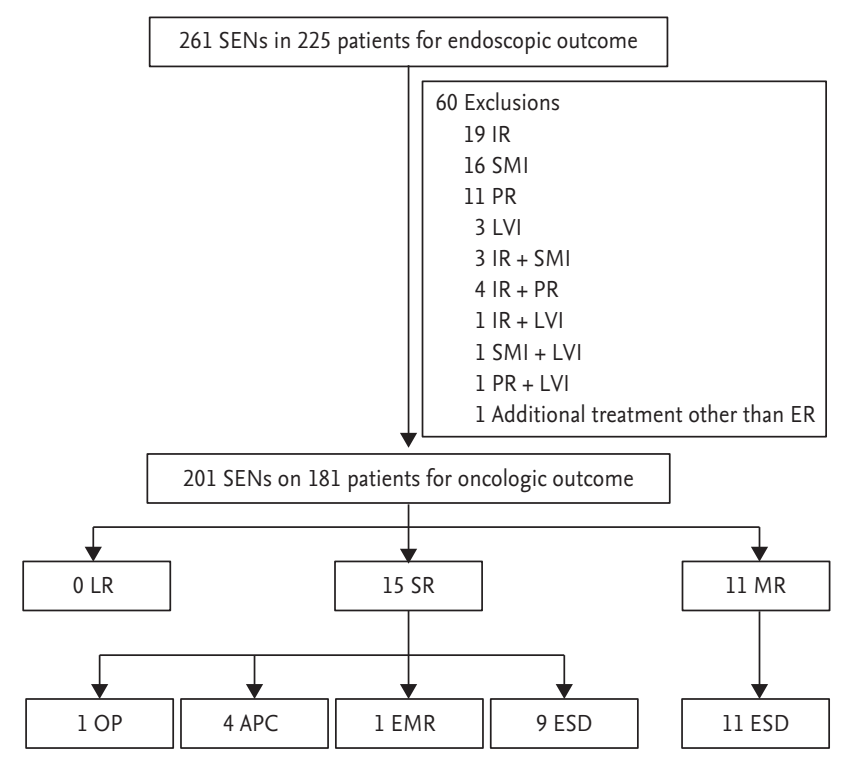

Figure 1. Clinical course of patients with curative resection. Among the study population, curative resection was achieved in 201 cases of superficial esophageal neoplasm after endoscopic submucosal dissection. The remaining 60 cases were classified into non-curative resection after histopathological evaluation because of incomplete resection, submucosal invasion (SMI), lymphovascular invasion (LVI), or piecemeal resection (PR). Oncologic outcome was evaluated for 201 superficial esophageal neoplasms (SENs) in 181 patients. IR, incomplete resection; ER, endoscopic resection; LR, local recurrence; SR, synchronous recurrence; MR, metachronous recurrence; OP, operation; APC, argon plasma coagulation; EMR, endoscopic mucosal resection; ESD, endoscopic submucosal dissection.

as perforation during the endoscopic procedure were treated by clipping during the procedure, and three patients diagnosed by chest radiography performed after the procedure were placed under careful observation. All patients with perforation recovered uneventfully without the need for further intervention. Among the patients with stricture, seven complained of dysphagia. Of these, five were managed with endoscopic balloon dilatation (EBD) and two were left untreated because they refused treatment. In contrast to lesions involving less than three-fourths of the luminal circumference ( $\mathrm{n}$ $=250$ ), lesions involving more than three-fourths of the luminal circumference $(\mathrm{n}=11)$ tended to be associated with a higher rate of stricture with a statistically significant difference ( $4.8 \%$ vs. $45.5 \%, p<0.001$ ).

Of 60 patients with non-CuR, 22 patients underwent additional treatment (esophagectomy, $\mathrm{n}=10$; radiation therapy, $\mathrm{n}=5$; concurrent chemoradiation, $\mathrm{n}=4$; 


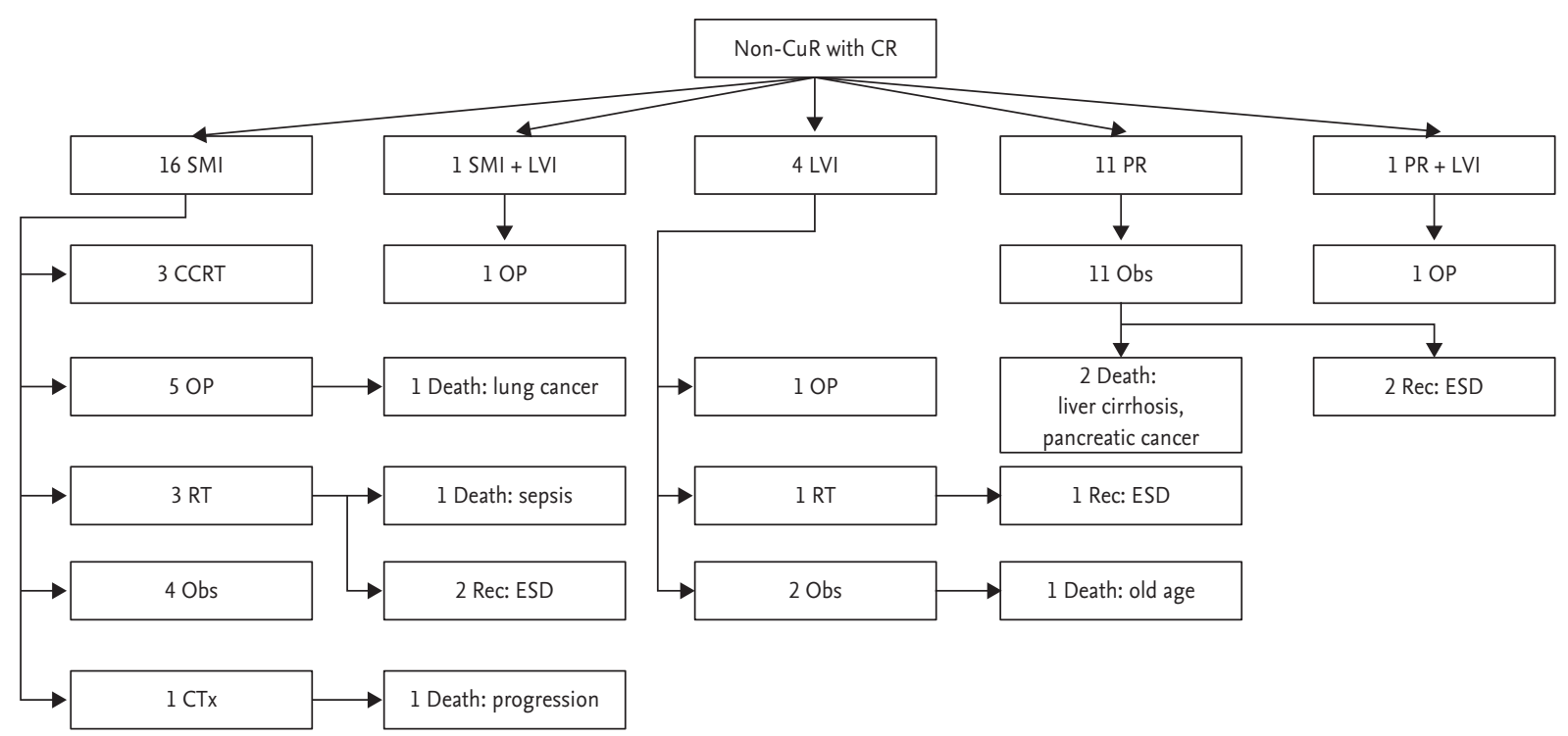

Figure 2. Long-term outcomes of patients with complete but non-curative resection (non-CuR) of superficial esophageal neoplasm. Among six patients who did not undergo additional treatment because of old age or patients' refusal, none showed recurrence, and only one patient died of an unrelated cause during the follow-up period. CR, complete resection; SMI, submucosal invasion; LVI, lymphovascular invasion; PR, piecemeal resection; CCRT, chemoradiation; OP, operation; Obs, observation; Rec, recurrence; ESD, endoscopic submucosal dissection; RT, radiotherapy; CTx, chemotherapy.

additional ESD, $\mathrm{n}=2$; and chemotherapy, $\mathrm{n}=1$ ). The remaining 38 patients were placed under observation without additional treatment because of their old age or patients' refusal. Among patients with non-CuR, synchronous recurrence was detected in two patients (3.3\%) and metachronous recurrence was detected in seven patients (11.7\%) during the follow-up period. Of these, a total of seven patients died; one patient died of esophageal cancer-related death, and six patients died of unrelated cause, such as lung cancer $(\mathrm{n}=2)$, stomach cancer $(\mathrm{n}=$ $1)$, liver cirrhosis $(n=1)$, pancreas cancer $(n=1)$, and old age $(\mathrm{n}=1)$.

Of the 234 completely resected lesions, 33 were defined as non-CuR because of SMI, LVI, or PR. Among 16 patients with SMI in CR, 12 underwent additional treatment (esophagectomy in five, radiation or chemoradiation in six, and chemotherapy in one), and three of these patients died of disease progression, lung cancer, and sepsis. Four patients were followed without additional treatment because of patient refusal or old age, and showed no recurrence or death. One patient with SMI and LVI underwent esophagectomy and showed no recurrence or death. Among four patients with LVI, two underwent additional treatment (one with esophagectomy and one with radiation), and all of these patients were still alive at the time of the study. One of two patients who refused additional treatment died of old age. Eleven piecemeal resected patients were followed without any treatment, and two of these patients died of liver cirrhosis and pancreatic cancer. One patient with PR with LVI underwent esophagectomy and showed no recurrence or death (Fig. 2).

Oncologic outcomes were evaluated at 201 lesions that were resected curatively. Of the 201 lesions with $\mathrm{CuR}$, recurrence occurred in 26 patients (12.9\%), including 15 with synchronous lesions and 11 with metachronous lesions, at a median follow-up of 36 months (interquartile range, 18 to 61 ). The median duration from ER to recurrence was 15.9 months (range, 3 to 69). Synchronous lesions were treated by surgery $(\mathrm{n}=1)$, argon plasma coagulation $(n=4), \operatorname{EMR}(n=1)$, and $\operatorname{ESD}(n=9)$. All patients with metachronous lesions were treated with ESD, and none of them showed local recurrence (Fig. 1).

During the follow-up period (median, 35 months; interquartile range, 18 to 62 ), the 5 -year overall survival rate was $89.7 \%$ in a patients who underwent ESD. When survival was analyzed according to the depth of invasion (To, m1, m2 vs. m3 vs. SMI), the 5 -year cumulative survival rates were $91.7 \%, 80.2 \%$, and $79.1 \%$, respectively (log-rank, $p=0.061)$. A total of 20 patients died, but 


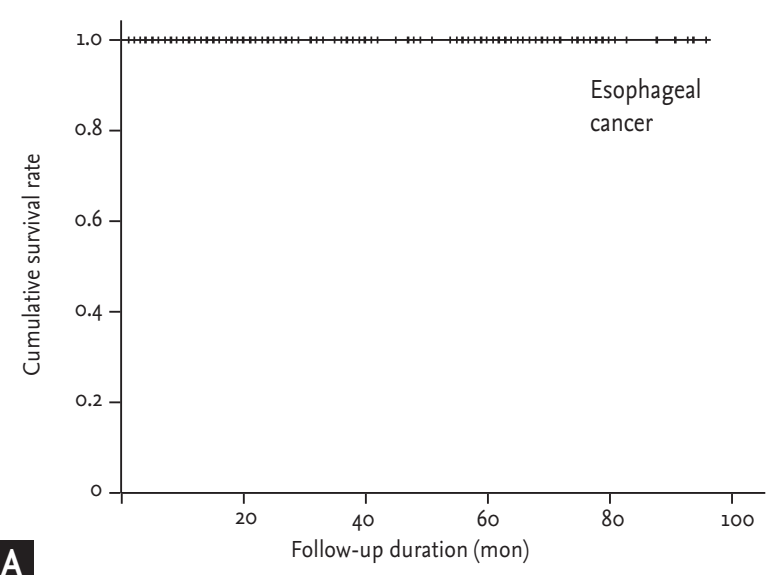

Figure 3. The results of survival analysis. (A) The 5-year disease-specific survival rates in curative resection patients and (B) the 5-year cumulative survival rates.

only one patient died of an esophageal cancer-related cause. When the 5-year disease-specific survival rate was evaluated in a patient with $\mathrm{CuR}, 14$ patients died of a non-esophageal cancer-related cause, and the 5-year disease-specific survival rate was 100\% (Fig. 3).

\section{DISCUSSION}

In the present study, we investigated the long-term clinical outcomes of ESD for SENs. The overall EnR, CR, and CuR rates were $93.9 \%, 89.7 \%$, and $77.0 \%$, respectively. Adverse events occurred in 33 patients (12.6\%), including bleeding (1.5\%), perforation (4.6\%), and stricture (6.5\%). The local tumor recurrence rate was $\% \%$ during a median follow-up period of 35 months. The 5 -year overall and disease-specific survival rates were $89.7 \%$ and $100 \%$, respectively. To the best of our knowledge, this is the largest study in Korea to evaluate the clinical outcomes of ESD of SENs with long-term follow-up data.

The Japanese Esophageal Society guidelines indicate that ER is recommended in patients with SENs limited to the intraepithelial (m1) and lamina propria layer (m2) without vascular invasion or lymph node metastasis [30]. In cases showing tumor invasion to the muscularis mu$\operatorname{cosa}\left(\mathrm{m}_{3}\right)$ or the submucosa $<200 \mu \mathrm{m}$ from the muscularis mucosa ( $\mathrm{sm1}$ ), ER should be decided based on the risk of lymph node metastasis because the incidence of lymph node metastasis is known to be associated with the depth of invasion [23,31]. There have been efforts to

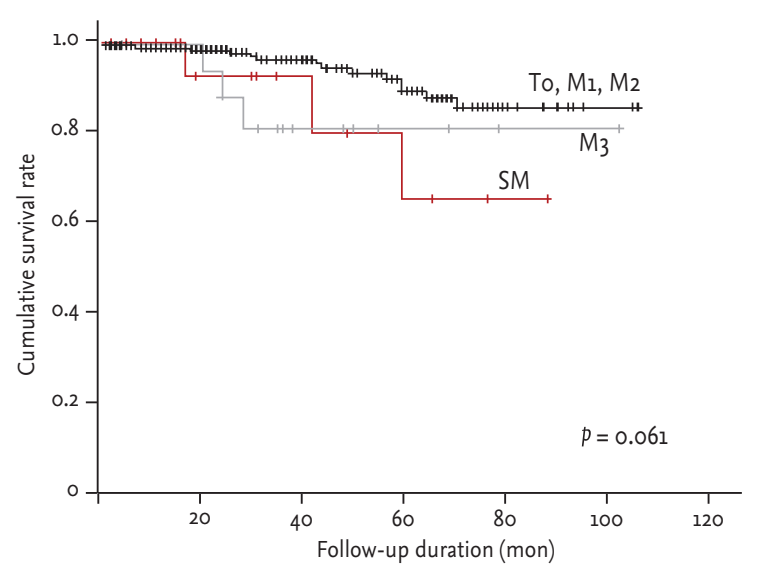

B

expand the indications for ESD, based on reported favorable outcomes of ER for $\mathrm{m} 3$ or sm1 tumors [11,32,33]. One study recommended ER when the SEN had a size less than $25 \mathrm{~mm}$, a lamina propria invasion width of less than $2,500 \mu \mathrm{m}$, and no evidence of lymphatic invasion [33]. The other study suggested that patients with $\mathrm{m} 3$ tumors should be carefully observed without additional treatment after ER, especially when the invasion width of the lower muscularis mucosa was less than 3,000 $\mu \mathrm{m}$ [26]. Although these studies analyzed a relatively small number of patients, most patients did not show lymph node or distant metastasis. In our study, none of the patients showed local recurrence, including $\mathrm{m}_{3}$ and sm1 tumors, which is consistent with the results of previous studies. These findings indicate that in elderly patients with comorbidities and minute submucosal invasive cancer, ER can be the most effective alternative to surgery. In addition, given that most patients with SEN are diagnosed when in old age, the decision to perform additional treatment after non-CuR should be taken carefully, depending on the patient's comorbidity and medical fitness.

The major adverse events associated with ESD are bleeding, perforation, and stricture. In the present study, perforation occurred in 12 patients (4.6\%), which is comparable to that of previous studies $[16,22,34]$, and were managed successfully with endoscopic management. Post-ESD stricture is a major concern because it is associated with impaired quality of life. The possibility of stricture is known to be increased when the circum- 
ference of the lesion exceeds three-fourths of the total circumference of the esophagus [30,35-37]. In addition, longitudinal mucosal defects longer than $30 \mathrm{~mm}$ are a significant risk factor for the development of esophageal stricture [22]. In the present study, stricture was detected in 17 cases $(6.5 \%)$ and the risk of stricture was higher in patients with lesions involving more than $3 / 4$ of the luminal circumference. Post-ESD stricture can be successfully managed with EBD [33]. Local injection or oral administration of steroids was recently reported as an effective strategy for preventing post-ESD stricture [3843]. Among patients with symptoms, five patients were successfully managed with EBD performed in a median of 1.6 sessions (range, 1 to 3 ). One patient underwent a single session of intralesional steroid injection that was performed immediately after near-circumferential ESD to prevent post-ESD stricture and showed a favorable outcome without structure or dysphagia [43].

In our study, the overall recurrence rate was $13.0 \%$, including 15 synchronous and 11 metachronous SENs during a median follow-up period of 37.1 months. Most recurrences occurred within 16 months (range, 3 to 69) of the initial ER. In addition, previous studies have shown that most local recurrences occur within 1 year after initial ER and might develop after 2 to 3 years $[17,19]$. Although there is no established guideline for the follow-up schedule after ER, endoscopic surveillance during the first 2 years after ER is essential for the early detection of local recurrence as well as synchronous or metachronous SENs.

The present study had several limitations. First, the retrospective study design may have caused a potential bias in the analysis. Second, the study was performed at a single center, which may have resulted in selection bias and referral bias. Third, the patients were selected for ESD according to the clinical judgment of physicians at the time of treatment, which involved consideration of patients' needs. Fourth, clinical outcomes may have been influenced by the endoscopists' experience because ESD is an operator-dependent procedure. However, our study provides consolidative data showing favorable long-term outcomes of ESD for a large number of cases of SEN over a 10-year period at one of the major referral centers in Korea.

In conclusion, the long-term follow-up data presented in this study indicates that ESD is a feasible and effec- tive procedure for the treatment of SENs and all patients treated by ESD should be maintained on a scheduled surveillance program. Tailored management after ESD could result in acceptable oncologic outcomes for patients with SENs, and a scheduled surveillance program should be pursued after ESD for the early detection of recurrence.

\section{KEY MESSAGE}

1. Endoscopic submucosal dissection is a safe and effective curative therapy for superficial esophageal neoplasms, based on 10-year's experience.

\section{Conflict of interest}

No potential conflict of interest relevant to this article was reported.

\section{REFERENCES}

1. Siegel R, Ma J, Zou Z, Jemal A. Cancer statistics, 2014. CA Cancer J Clin 2014;64:9-29.

2. Jemal A, Bray F, Center MM, Ferlay J, Ward E, Forman D. Global cancer statistics. CA Cancer J Clin 2011;61:69-90.

3. Jung KW, Won YJ, Kong HJ, Oh CM, Seo HG, Lee JS. Cancer statistics in Korea: incidence, mortality, survival and prevalence in 2010. Cancer Res Treat 2013;45:1-14.

4. Kumagai Y, Monma K, Kawada K. Magnifying chromoendoscopy of the esophagus: in-vivo pathological diagnosis using an endocytoscopy system. Endoscopy 2004;36:590594.

5. Yoshida T, Inoue H, Usui S, Satodate H, Fukami N, Kudo SE. Narrow-band imaging system with magnifying endoscopy for superficial esophageal lesions. Gastrointest Endosc 2004;59:288-295.

6. Kodashima S, Fujishiro M, Takubo K, et al. Ex-vivo study of high-magnification chromoendoscopy in the gastrointestinal tract to determine the optimal staining conditions for endocytoscopy. Endoscopy 2006;38:1115-1121.

7. Kato H, Tachimori Y, Watanabe H, Yamaguchi H, Ishikawa T, Itabashi M. Superficial esophageal carcinoma: surgical treatment and the results. Cancer 1990;66:2319-2323.

8. Kato H, Tachimori Y, Mizobuchi S, Igaki H, Ochiai A. Cer- 
vical, mediastinal, and abdominal lymph node dissection (three-field dissection) for superficial carcinoma of the thoracic esophagus. Cancer 1993;72:2879-2882.

9. Roth JA, Putnam JB Jr. Surgery for cancer of the esophagus. Semin Oncol 1994;21:453-461.

10. Pech O, Gossner L, May A, Vieth M, Stolte M, Ell C. Endoscopic resection of superficial esophageal squamous-cell carcinomas: Western experience. Am J Gastroenterol 2004;99:1226-1232.

11. Higuchi K, Tanabe S, Koizumi W, et al. Expansion of the indications for endoscopic mucosal resection in patients with superficial esophageal carcinoma. Endoscopy 2007;39:36-40.

12. Ciocirlan M, Lapalus MG, Hervieu V, et al. Endoscopic mucosal resection for squamous premalignant and early malignant lesions of the esophagus. Endoscopy 2007;39:24-29.

13. Pech O, May A, Gossner L, et al. Curative endoscopic therapy in patients with early esophageal squamous-cell carcinoma or high-grade intraepithelial neoplasia. Endoscopy 2007;39:30-35.

14. Ono H, Kondo H, Gotoda T, et al. Endoscopic mucosal resection for treatment of early gastric cancer. Gut 2001;48:225-229.

15. Oyama T, Tomori A, Hotta K, et al. Endoscopic submucosal dissection of early esophageal cancer. Clin Gastroenterol Hepatol 2005;3(7 Suppl 1):S67-S70.

16. Ishihara $\mathrm{R}$, Iishi $\mathrm{H}$, Uedo $\mathrm{N}$, et al. Comparison of EMR and endoscopic submucosal dissection for en bloc resection of early esophageal cancers in Japan. Gastrointest Endosc 2008;68:1066-1072.

17. Katada C, Muto M, Manabe T, Ohtsu A, Yoshida S. Local recurrence of squamous-cell carcinoma of the esophagus after EMR. Gastrointest Endosc 2005;61:219-225.

18. Esaki M, Matsumoto T, Hirakawa K, et al. Risk factors for local recurrence of superficial esophageal cancer after treatment by endoscopic mucosal resection. Endoscopy 2007;39:41-45.

19. Ishihara $R$, Iishi $H$, Takeuchi $Y$, et al. Local recurrence of large squamous-cell carcinoma of the esophagus after endoscopic resection. Gastrointest Endosc 2008;67:799804.

2o. Hammad H, Kaltenbach T, Soetikno R. Endoscopic submucosal dissection for malignant esophageal lesions. Curr Gastroenterol Rep 2014;16:386.

21. Ishihara $\mathrm{R}$, Tanaka $\mathrm{H}$, Iishi $\mathrm{H}$, et al. Long-term outcome of esophageal mucosal squamous cell carcinoma without lymphovascular involvement after endoscopic resection. Cancer 2008;112:2166-2172.

22. Takahashi H, Arimura Y, Masao H, et al. Endoscopic submucosal dissection is superior to conventional endoscopic resection as a curative treatment for early squamous cell carcinoma of the esophagus (with video). Gastrointest Endosc 2010;72:255-264, 264.e1-e2.

23. Yamashina T, Ishihara R, Nagai K, et al. Long-term outcome and metastatic risk after endoscopic resection of superficial esophageal squamous cell carcinoma. Am J Gastroenterol 2013;108:544-551.

24. Repici A, Hassan C, Carlino A, et al. Endoscopic submucosal dissection in patients with early esophageal squamous cell carcinoma: results from a prospective Western series. Gastrointest Endosc 2010;71:715-721.

25. Ono S, Fujishiro M, Niimi K, et al. Long-term outcomes of endoscopic submucosal dissection for superficial esophageal squamous cell neoplasms. Gastrointest Endosc 2009;70:860-866.

26. Kim DH, Jung HY, Gong EJ, et al. Endoscopic and oncologic outcomes of endoscopic resection for superficial esophageal neoplasm. Gut Liver 2015;9:470-477.

27. Kodama M, Kakegawa T. Treatment of superficial cancer of the esophagus: a summary of responses to a questionnaire on superficial cancer of the esophagus in Japan. Surgery 1998;123:432-439.

28. Japan Esophageal Society. Japanese Classification of Esophageal Cancer, tenth edition: part I. Esophagus 2009;6:1-25.

29. Chiba T, Kawachi H, Kawano T, et al. Independent histological risk factors for lymph node metastasis of superficial esophageal squamous cell carcinoma: implication of claudin-5 immunohistochemistry for expanding the indications of endoscopic resection. Dis Esophagus 2010;23:398-407.

30. Ono S, Fujishiro M, Niimi K, et al. Predictors of postoperative stricture after esophageal endoscopic submucosal dissection for superficial squamous cell neoplasms. Endoscopy 2009;41:661-665.

31. Fujita H, Sueyoshi S, Yamana H, et al. Optimum treatment strategy for superficial esophageal cancer: endoscopic mucosal resection versus radical esophagectomy. World J Surg 2001;25:424-431.

32. Katada C, Muto M, Momma K, et al. Clinical outcome after endoscopic mucosal resection for esophageal squa- 
mous cell carcinoma invading the muscularis mucosae: a multicenter retrospective cohort study. Endoscopy 2007;39:779-783.

33. Shimizu Y, Tsukagoshi H, Fujita M, Hosokawa M, Kato M, Asaka M. Long-term outcome after endoscopic mucosal resection in patients with esophageal squamous cell carcinoma invading the muscularis mucosae or deeper. Gastrointest Endosc 2002;56:387-390.

34. Fujishiro M, Yahagi N, Kakushima N, et al. Endoscopic submucosal dissection of esophageal squamous cell neoplasms. Clin Gastroenterol Hepatol 2006;4:688-694.

35. Mizuta H, Nishimori I, Kuratani Y, Higashidani Y, Kohsaki T, Onishi S. Predictive factors for esophageal stenosis after endoscopic submucosal dissection for superficial esophageal cancer. Dis Esophagus 2009;22:626-631.

36. Messmann H, Probst A. Management of endoscopic submucosal dissection complications. Endoscopy 2009;41:712-714.

37. Shi Q, Ju H, Yao LQ, et al. Risk factors for postoperative stricture after endoscopic submucosal dissection for superficial esophageal carcinoma. Endoscopy 2014;46:640644 .

38. Sato H, Inoue H, Kobayashi $\mathrm{Y}$, et al. Control of severe strictures after circumferential endoscopic submucosal dissection for esophageal carcinoma: oral steroid therapy with balloon dilation or balloon dilation alone. Gastrointest Endosc 2013;78:250-257.

39. Yamaguchi N, Isomoto $H$, Nakayama $T$, et al. Usefulness of oral prednisolone in the treatment of esophageal stricture after endoscopic submucosal dissection for superficial esophageal squamous cell carcinoma. Gastrointest Endosc 2011;73:1115-1121.

40. Yamaguchi N, Isomoto $\mathrm{H}$, Shikuwa S, et al. Effect of oral prednisolone on esophageal stricture after complete circular endoscopic submucosal dissection for superficial esophageal squamous cell carcinoma: a case report. Digestion 2011;83:291-295.

41. Isomoto H, Yamaguchi N, Nakayama T, et al. Management of esophageal stricture after complete circular endoscopic submucosal dissection for superficial esophageal squamous cell carcinoma. BMC Gastroenterol 2011;11:46.

42. Hashimoto S, Kobayashi M, Takeuchi M, Sato Y, Narisawa $\mathrm{R}$, Aoyagi $\mathrm{Y}$. The efficacy of endoscopic triamcinolone injection for the prevention of esophageal stricture after endoscopic submucosal dissection. Gastrointest Endosc 2011;74:1389-1393.

43. Lee WJ, Jung HY, Kim DH, et al. Intralesional steroid injection to prevent stricture after near-circumferential endosopic submucosal dissection for superficial esophageal cancer. Clin Endosc 2013;46:643-646. 